Article

\title{
You Are How You Eat? Femininity, Normalization, and Veganism as an Ethical Practice of Freedom
}

\author{
Megan A. Dean \\ Department of Philosophy, Georgetown University, 215 New North Hall, 37th and O Streets, NW, \\ Washington, DC 20057, USA; E-Mail: mad301@ georgetown.edu; Tel.: +1-202-815-0891
}

Received: 5 March 2014; in revised form: 27 March 2014 / Accepted: 2 April 2014 /

Published: 10 April 2014

\begin{abstract}
In this paper I argue that the practice of veganism is, or can be, a Foucauldian ethical practice of freedom. I begin by sketching out the problematization of alimentary practices within a normalizing patriarchal framework, which some feminists argue is dominant within contemporary North American society. Within this problematization, eating - for many women - is a way to manage the body's appearance and bring it into conformity with feminine norms, and also an ongoing opportunity to exercise the will over unruly bodily desires. I then consider the narratives of women who claim that veganism helped them to relinquish disordered eating habits, temper the emotional and psychological turmoil that surrounded their alimentary practices, and mitigate antagonism toward their own bodies. In short, the practice of veganism appears to have reproblematized eating for these women. Thus, I suggest, veganism can be an ethical practice of freedom: it can loosen the tight grip of patriarchal normalization as constituted in and through disordered eating habits, and constitute subjects that are "a little less governed" by this form of power. I conclude by considering objections to this thesis, and in particular, the concern that veganism is linked to healthism, another worrying form of normalization.
\end{abstract}

Keywords: normalization; femininity; eating disorders; Foucault (Michel); diet; ethics; feminism

\section{Introduction}

North Americans are infatuated with food. Some would say obsessed. We love to talk about food, daydream about food, break food down into nutritional counts and carb loads and fat content, find out about our food's origins and the chemicals it was sprayed with and who eats what and how much and 
at what time, and argue about whether or not that's best. From a Foucauldian perspective, this proliferation of discourse indicates that food and eating are significant to our identities. Chloë Taylor [1] argues that in the contemporary West eating, or, more broadly, diet, is a locus of what Foucault calls ethical practice; that is, our alimentary practices, the ways we make and eat and think and talk about food, are central to the constitution, reinforcement, and transformation of our subjectivities, to who we are in a deep sense. ${ }^{1}$

Taylor contends that as such a self-constituting practice, eating is the target of various apparatuses of discipline and normalization. Cultural, political, and social institutions, groups, and media guide or influence (in more and less intentional ways) our alimentary practices, and thereby shape our subjectivities in accordance with various norms-norms of race, gender, sexuality, ethnicity, socio-economic class, and so on. This view is congruent with the work of feminists like Sandra Bartky [2] and Susan Bordo [3], who have long pointed to diet as a target of patriarchal disciplinary power. Within contemporary patriarchal North American society, eating is problematized as a way to manage the body's appearance, to bring it into conformity with feminine norms, and also as an ongoing opportunity to exercise the will over unruly bodily desires. Since most women's bodies are far from the feminine "ideal" in and of themselves, this self-management entails heavy restriction, strict discipline, and steadfast self-surveillance. We're always supposed to be "watching our figures", precisely by "watching what we eat". In short: we become feminine (that is, feminine as defined by patriarchy), in a significant and deep sense, in and through our diets.

Cressida Heyes [4] characterizes this disciplined dieting as one flavour of "corporeal normalization": the injunction to realize one's "true self"-located somewhere "inside" oneself—on the body. According to Heyes, feminine dietary practices and others inspired by corporeal normalization foster "a miserable, earnest meekness about ourselves that is wrapped up with stereotypical femininity, institutional control, and impoverished relations to others" [4] (p. 112). More bluntly, Bartky alleges that these "feminine" alimentary practices constitute women as docile subjects of patriarchal power [2] (p. 66), making them complicit in its continued dominance. Concern with patriarchy aside, it is clear to me that for many women this way of eating is a great source of pain, anxiety, self-doubt, and distraction from other, less Sisyphean and potentially more joyful projects.

So, what can be done? The complications of resisting what we experience as our own true selves, or at least significant bits of ourselves, are discouraging. However, some Foucault scholars, Taylor and Heyes included, have argued that Foucault offers us a tractable path for resistance through the notion of ethical practices of freedom: the strategic experimentation with various ethical practices in the hopes of constituting a self that is not governed "quite so much". If eating is indeed an ethical practice, then we might experiment with new ways of eating, and perhaps find ways to "eat ourselves away from" docile, normalized identities. ${ }^{2}$

In this paper I consider the possibility that the practice of veganism is, or can be, an ethical practice of freedom. I begin by introducing the key theoretical notion of normalization, and link it with an

\footnotetext{
I will use "eating", and sometimes "diet", as short hand for alimentary practices throughout the paper.

2 This phrasing may be misleading. It is necessary, on my view, to always be "practicing" ourselves into new identities or subjectivities rather than just practicing ourselves out of the ones we already have. In other words, we can't just erase the unsavory identity and be left with nothing, or something neutral.
} 
analysis of the place of diet within contemporary patriarchal systems. I then outline an account of ethical practices of freedom. Next, I draw out several themes from narratives taken from the blog series "Green Recovery", hosted by Gena Hamshaw at her blog Choosing Raw [5], which I believe indicate a significant ethical shift away from the normalizing, patriarchal problematization of eating. I read the narratives of vegans who claim that their practice of veganism helped them to relinquish disordered eating habits, temper the emotional and psychological turmoil that surrounded their eating practices, and mitigate antagonism toward their own bodies. These stories suggest that veganism can loosen the tight grip of patriarchal corporeal normalization as constituted in and through disordered eating habits, and constitute subjects that are a little less governed. ${ }^{3}$ I conclude by considering two objections to my argument: first, that veganism, or more broadly, vegetarianism is itself an eating disorder; and second, that veganism, or at least the veganism practiced by the contributors to Green Recovery, is dangerously linked to healthism, another worrying form of normalization.

\section{Normalization}

The central theoretical concept I use throughout this paper is normalization. Normalization is a set of techniques of power which posit a standard or norm against which subjects are measured and thereby come to be defined as individuals. The idea comes from Foucault's work on disciplinary power, where he introduces the notion of normalizing judgment as a central disciplinary technique. In the context of a disciplinary institution, like the school or the prison, the disciplinarian uses normalizing judgment to evaluate and punish not only violations of rules, but also the failure of subjects to meet certain standards or norms. Normalizing judgment homogenizes and individualizes subjects by first, considering all members of a group with reference to a particular norm (for example, the ideal fifth grade student) and second, by differentiating persons or "individuals" by their relation to the norm and to each other (for example, "A" students or remedial students) [6] (p. 184). This normalized ranking is understood to reveal something important about the individuals in question - "their nature, their potentialities, their level or their value" [6] (p. 181) —not simply their actions. In other words, a subject's actions, and in particular their relation to the norm, are taken as deeply representative of the subject herself.

Pain, or the threat of pain, is a primary tool for normalizing institutions or, more broadly, "regimes" [7] (p. 179), and is used to force subjects into compliance with practices and norms. Pleasure has a place here too: Heyes describes normalizing practices as using "cycles of pain interspersed with brief windows of pleasure to keep subjects dependent on their authority" [4] (p. 121). In the disciplinary institution, there is punishment for failing to meet a norm, with attendant shame and embarrassment, and pleasurable rewards for living up to a norm. ${ }^{4}$ Within a less institutional regime, there are affective "punishments" and rewards, and, as we shall see, social ones.

3 This paper is not meant as an exhaustive consideration of the resistant (or normalizing) possibilities of veganism, nor as an exhaustive account of possible alimentary practices of freedom. It is also not meant to suggest that veganism is somehow a "cure" for disordered eating.

4 Normalizing judgment explicitly gives standards a normative force-one should conform to, or at least work toward that standard. Once one has been identified in relation to the norm, one is called to compensate for one's failings 
Individuals achieve a norm through engagement in particular disciplinary practices, which aim to create capacities necessary for or constitutive of the norm (for example, our fifth grader doing her math homework). Undertaking these normalizing disciplinary practices reveals our commitment to reaching the norm, and participation is these practices is also often seen as the only way to assuage the suffering created by failure to reach normative standards [4] (p. 121). By calling for or compelling normalizing practices, normalizing regimes guide action. It is in this sense that we can speak of normalizing power; Foucault defines power as "an action upon an action, on possible or actual future or present actions" [8] (p. 340). Further, because subjects are constituted through practices, on Foucault's view, by pursuing the norm through normalizing practices, we become normalized selves: defined in relation to the norm, located somewhere along the trajectory that ends at its attainment.

\section{Normative Femininity and Diet}

While Foucault was primarily (or at least explicitly) focused on institutions, normalizing regimes can be unattached from institutions, functioning in an amorphous manner throughout society. Bartky characterizes modern patriarchy as just such a regime. Within contemporary North American patriarchy, femininity is itself a norm (masculinity as well), one taken to be natural or essential to female persons qua their sex. On Bartky's view, all female human beings are homogenized and individualized in reference to this norm, regardless of their race or class (and presumably, sexuality) [2] (p. 72). Bordo argues along similar lines, noting that although there may be differences in beauty ideals amongst different racial, ethnic, or class groups, there is nonetheless significant cultural homogeneity with regard to this general feminine norm [3] (p. 63). Unlike norms imposed by Foucault's disciplinary institutions, which one could conceivably get out of (the norm of a good soldier no longer applies if one leaves the army, for instance), norms of femininity and masculinity are supposedly natural and innate. They are in you from birth, and there is no escaping them. This link with an ostensibly natural, biological sex serves to disguise the contingency of gender norms; realizing one's "true gender" is integral to "becoming who we really are". 5

Bartky sketches out three aspects of the contemporary feminine norm: a particular body shape, size, and composition; bodily gestures and comportments; and the body as "ornamented surface" [2] (p. 65). The first is the most relevant for our purposes, as it is most closely linked to alimentary practices. ${ }^{6}$

through better (or more) disciplinary practice. It is a personal failure to not do so; one must show one's proper comportment and respect for the norm through engagement in disciplinary practices.

5 It at the same time serves to pathologize anyone who cannot, or does not, become who they "really" are. As Heyes [4] points out, identities form around recalcitrant failures to meet the norm, as with the institution of homosexuality as an identity. Once this happens, a normalizing structure is deployed within this "abnormal" identity as well. On another note, although masculinity is also a norm, its content is much different from the feminine (cf., [9]) and the effects of those engaged in the normative project of masculinity are much different. If men achieve masculinity, they have real world power; but as Bartky [2] tells us, a woman who achieves normative femininity is still only just a woman.

6 One example of normative feminine gestures and comportments is the way women sit in a closed, tightly compact way, taking up as little space as possible. The ornamentation of the feminine body includes the way the body smells, the smoothness and hairlessness of the skin, and facial features like rosy cheeks and long eyelashes which, if not "gifted" by nature, must be approximated with cosmetic techniques or procedures. Women are beholden to norms in all three of 
Today's ideal feminine shape, size and composition is perhaps a bit more muscular and with bigger breasts than the one Bartky [2] describes in 1990 (cf., [3] (p. xvi)), but is nonetheless still very slim, tight or compact, and self-contained [3] (pp. xiii-xxxiii).

Diet (read as the controlled practice of eating) is a central disciplinary practice of normative femininity, one of the main practices used to manage the body's shape and composition. Diet is also an ongoing opportunity to exercise the will over one's bodily desires, thereby showing an appropriately feminine appetite and self-control. As contemporary patriarchy is largely "unnattached" to an institution, there is no one particular person or group who act as disciplinarians for this normalizing dieting project; rather, as Bartky says, everyone acts as disciplinarians [2] (p. 79). Many women, especially those considered "overweight" can attest to the fact that strangers and others will act as de facto disciplinarians, either encouraging disciplinary practices, doling out social rewards when one has lost weight or is perceived as trying to do so, or shaming those who appear non-compliant [2] (p. 74); [10] (p. 10). However, as Bartky shows, the disciplinarian is internalized as well [2] (p. 80); women practice constant self-surveillance, exercising normative judgment on themselves, ranking themselves in relation to the norm and to the other women engaged in the same project.

\section{Diet as a Practice of the Self}

Following Chloë Taylor, I want to understand eating as a Foucauldian practice of the self, or ethical practice. According to Foucault, ethics can be understood as the actions of the self on the self with the aim of making, developing, or transforming the self to reach a particular state of being [11] (p. 291). Unlike practices of knowledge or power, where one often relates to others and to institutions, practices of the self are based on a relationship to oneself - to one's desires, thoughts, rationality, and so on. It is through these practices that the self is constituted, reinforced, and transformed.

Foucault offers us a four point model to analyze ethical practices. The first aspect of ethical practice is the ethical substance, or the part of the self which is ethically or morally relevant [12] (p. 263). This is the part of the self upon which work is done, or which the work aims to alter: one's sexual behaviour, or one's desires and thoughts, for instance. The second aspect is the mode of subjectivation, the way one is called to engage in the ethical project [12] (p. 264). One might engage in ethical practice because it is a religious imperative or because one's sense of humanity demands it, for example. The next aspect is ethical work, "self-forming activity", or the means of transforming the self into an ethical subject [12] (p. 265). This is the precise practice one engages in to transform the self, such as reporting one's thoughts in a journal or the confession of one's sexual behaviours to a religious authority. The final aspect is the telos, or goal - the type of individual which the ethical practice aims to create or realize [12] (p. 265). For instance, one could aim to be a pure person, a rational person, or an authentic one. ${ }^{7}$

these areas; a "hot body" with the wrong clothes, a sweaty smell, or a unibrow fails to achieve normative femininity, just as the fat person with the pretty face.

7 It is important to distinguish this framework from a means/ends structure of motivation. Intentions are relevant, but the ethical framework should be identifiable from the "outside". It is not simply what the person claims to be doing but what makes the practice possible and intelligible in a more general sense. 
So, what is the ethical framework of eating within a system of normative patriarchy? First, the ethical substance: the part of the self a diet works on is desire, appetite, hunger. Second, we are called to engage in this project by our innate and natural femininity, guaranteed by biological and physiological factors. This norm has force insofar as we believe it to be and experience it as who we really are. In a culture of authenticity in particular, failing to realize one's inner truth is a failing of the self. Thirdly, the actual "self-forming activities" captured by a diet are multiple. There is the literal practice of eating, which entails food preparation, meal planning, the counting of calories or fat grams or carbs (and so on), unending education on nutrition or diet tips; there is also the practice of weighing oneself, keeping oneself "honest" by food journaling, engaging in diet support groups whether online or in person, managing hunger in various ways, and so on. Finally-what is the telos? It is, at first glance, to get to one's "goal weight". More richly, it is to master one's unruly or "unhealthy" desires, or to eradicate them; and, as Heyes' analysis shows, it is to have one's outer self match the inner, where the inner is a thin, beautiful, self-contained woman who does not struggle with food or her desires to eat, and always eats the perfect amount.

These alimentary practices are premised on, and reinforce, a despotic and antagonistic relation to oneself, and in particular, to one's body and desires. ${ }^{8}$ According to Susan Bordo, this relationship is made possible by the Western separation of body and mind, which she locates in philosophical discourse. Such philosophies characterize the body as alien, confinement or limitation, enemy, and "the locus of all that threatens our attempts at control" [3] (p. 145). ${ }^{9}$ The fact that the ideal feminine body (in terms of size and composition) is not "naturally occurring" for most women, and, in general, requires a "downsizing", makes the body and its needs something to be combatted: "since the innocent need of the organism for food will not be denied, the body becomes one's enemy, an alien being bent on thwarting the disciplinary project" [2] (p. 66). Thus the self (identified with the mind or the will, and set against the body) must take a dictatorial relation to one's body, to control its unruly desires, appetites, and urges (cf., [3], pp. 148-154). On a Foucauldian view, the more one engages in such behaviours, the more solidly this dictatorial self is established, and the more this agonistic relation with the self is taken for granted.

Bartky argues that it takes an immense amount of work to even approximate normative femininity. ${ }^{10}$ The patriarchal disciplinary practices of femininity are multiple, intensive, and, thanks to the normalization of femininity, nearly obligatory as an expression of "natural" gender and sex. The multiplicity of necessary practices, or, in other words, the fact that many women do not "naturally" conform to the norm does not throw the norm itself into question; rather, it reflects on each individual's inadequacies or deviances. The pain invoked by this normalizing schema is pervasive and nearly constant. There is pain in failing to meet the norm, pain in failing to do the normative practices adequately; and even pain in struggling with the normative practices, not finding them easy or natural.

8 Cf., [4] (p. 9).

9 Fat studies scholars have shown that in contemporary society these attributes are not given to the body in general, but localized in fat and those desires and appetites that place us at constant risk of getting (more) fat [13,14].

10 Bartky claims that the norms of femininity are "impossible to realize, requiring as they do a virtual transcendence of nature" [2] (p. 80), generating experiences of constant bodily failure. The experience of failure inspires further engagement in disciplinary practices, seemingly the only options to mitigate the suffering following from such failure. Hence, as Bartky says, "the compulsive or even ritualistic character" of these practices [2] (p. 72). 
Even if one manages to find pleasure in reaching one's "goal weight", or mastering one's desires and abstaining from "tempting" desserts, this pleasure is fleeting; maintaining the weight is a new disciplinary project in itself (and some people might suggest you could stand to lose a little more), and it is only a matter of time until the next pang of hunger or "craving". In part this is a function of normalizing projects in general; once you achieve a norm, you need to continue to practice in order to maintain this achievement (for example, even the excellent soldier must continue to drill lest she lose her abilities to fight), or you get taken up into a new normalizing schema-a new grade in school, for instance, where a new norm applies, and you start again. Nevertheless, the moments of achievement provide genuine and intoxicating pleasure - and in the case of diet, there is plenty of social reward to go along with it, as anyone who has lost a noticeable amount of weight will attest [4] (p. 78); [10] (p. 10); [13] (p. 118).

\section{Ethical Practices of Freedom}

I have sketched out the shape and meaning of alimentary practices within a contemporary, normalizing patriarchal framework. In this framework eating is mainly a means of producing a body that meets feminine norms for shape, size, and composition. It is also a site where the will may conflict with desires and appetites, bringing the strength and direction of these bodily forces into sharp relief and constituting a daily test of self-control and will power. Not only does this way of eating require immense amounts of physical, intellectual, and emotional work, and engender myriad forms of physical and psychological suffering, but it posits a goal—an ideal body and the mastery of one's appetites - that is almost impossible to accomplish.

According to Susan Bordo's canonical analysis of anorexia [3], this problematization of eating is widespread throughout contemporary North American society. ${ }^{11}$ It crystallizes in forms of seriously disordered eating and eating disorders, but is present in a less concentrated form throughout. If we want to avoid being "docile subjects of patriarchy", or just get away from the pain and incessant work of "dieting", we are going to have to find ways to reproblematize eating. Foucault's ethical practices of freedom might be one way to do this. Foucault suggests that if we recognize the ways in which we are making ourselves through ethical practices, we can intentionally and thoughtfully engage in practices that produce different sorts of selves. We do not seek, nor do we require, entirely new practices. Rather, we want practices that are available to us which will help us practice ourselves into different, and hopefully less normalizing, ethical frameworks. In doing so, the hope is that we make ourselves in a way that is a little less "governed", or a little more "free". Some clarification of a Foucauldian understanding of freedom will be helpful here. Power is, as we have seen, the ways individuals interact with one another that influence each other's actions. This influence can be exercised in both positive - through encouragement or enticement - and negative - through restriction or force - ways. One seeks to influence anothers' actions precisely because there are a variety of possibilities for action. This indeterminacy of action, then, is one sense of freedom. But freedom is also a practice for Foucault; the practices that take advantage of, and create more of, such possibilities for

11 I accept that disordered eating and eating disorders are crystallization of cultures in large part, but this is not to say that there are not other factors at play, especially in the extreme cases. 
action [15] (p. 12). ${ }^{12}$ In this sense, ethical practices are practices of freedom because they take advantage of, and, ideally, open up more, possibilities for action.

Foucault insists that where there is no freedom there is no power: only domination [11] (p. 283). Domination occurs when power relations are rigid, asymmetrical, and extremely restrictive of actions and possibilities. When certain patterns of behavior become entrenched as religious imperatives or as medically necessary, for instance, a situation of domination can arise [16] (p. 148). Thus, Foucault writes, our task as ethical subjects is to practice our freedom while maintaining, and if possible, expanding, the freedom of ourselves and others: "to acquire the rules of law, the management techniques, and also the morality, the ethos, the practice of the self, that will allow us to play these games of power with as little domination as possible" [11] (p. 298).

This view of practices of freedom raises both practical and theoretical questions: How do we know which practices to try? How can we know if they are actually making us less governed? How do we know if they maintain or destroy the freedom of others? While I cannot fully address these questions here, I will point out a few general themes that might guide the search and success criteria for practices of freedom.

First, it will be helpful to know what ethical practices we are currently engaged in and the kinds of selves we are creating through them. This knowledge can come from various sources, including, Foucault suggests, sociological and historical analyses [17] (p. 132). ${ }^{13}$ Second, in contrast to the contemporary Western obsession with finding one's true self-which, as Heyes [4] argues, is a normalizing project-we might take a creative approach to our selves [19] (p. 166). In other words, we want to replace the (potentially) despotic relationship with ourselves with a creative or artistic relationship or stance [20] (p. 140). Taking the self as what Taylor [1] calls an ethico-aesthetic project emphasizes creativity and freedom in the cultivation of one's practices, rather than simply following the discipline one is given or working to reveal an essential self hiding somewhere inside. This necessitates a constant self-critique, an experimental attitude, and entails a focus on the process of making, trying, and testing out, rather than on the end product or telos. Third, practices of freedom can be disciplinary practices, but we need to separate the capacities we gain through these practices from obedience to a norm and the "narrowing of behavioural possibility", which usually accompanies it [7] (p. 180). Normative regimes encourage action and capacity-building but only in service to the norm; possibilities for action that are irrelevant or contrary to the normative trajectory are effectively closed off. Ladelle McWhorter insists that ethical practices of freedom should maintain a structural openness to possibilities through the rejection of static goals [7] (p. 193), especially those ends, which claim to be innate or natural to us. It is not that we should not set goals for ourselves at all; but any

12 Oksala [15] identifies four distinct uses of freedom in Foucault's work, only two of which are central to our discussions here. First, she posits freedom as ontological contingency, the fact that things need not be as they are. Secondly, there is freedom as ethics or the deliberate practice or realization of this ontological contingency. Freedom is also the ethos of the Enlightenment, adopted as a value by Foucault. Lastly, she defines freedom in a negative sense as the "precondition and permanent provocation of power" (p. 191). This is freedom as, by definition, a feature of power relations.

13 Genealogical analyses like Foucault's Discipline and Punish [6] and more contemporary ones like McWhorter's Racism and Sexual Oppression in Anglo-America [18], may be particularly helpful as they will throw into relief which practices are central to self-constitution in a given context, which sorts of power relations they reinforce, and the particular institutions involved. This can help us decide which practices to change. 
given end should remain open to question, revision, and abandonment. In the end, the ultimate telos of practices of freedom should be nothing more than "the expansion of behavioural options" [7] (p. 182).

In light of this rejection of static ends, disciplinary practices might be taken up for the pleasure they can provide in themselves [7] (p. 182). While disciplinary practices can be pleasurable in themselves, in most cases these pleasures are subservient to the norm. That is, disciplinary practices and their pleasures are not inherently valuable; they only matter insofar as they help one achieve the norm, and only permissible insofar as they do not interfere with our normative projects. ${ }^{14}$ However, this need not be the case; perhaps, for instance, we can take the pleasure of the physical exertion and movement of a dance class or a vigorous hike as a reason to engage in the practice, rather than doing so to burn calories or get "six-pack abs". Focusing on the pleasures engendered by the practices themselves may allow us to use disciplinary practices available to us without tying us to normalized selves, and thus maintain the openness to becoming central to practices of freedom.

Thus, if we are looking for a way to eat more freely, to be less governed by normalizing patriarchal power in and through our alimentary practices, we want a set of alimentary practices that are, first, for the sake of something other than the ideal feminine body and the mastery of desires and appetites. Whatever this new telos is, it should not be taken as natural, essential, or innate. Whatever telos we posit should remain open to revision or abandonment, and we should see our practices as experimental, as a means to expand our capacities and "behavioral options". In order to help us maintain this creative, experimental view, we want to find some pleasure in the practices themselves. Finally, we must aim to practice our freedom with as little domination as possible.

This way of sketching out practices of freedom is strikingly voluntarist, even if it is situated within a complex Foucauldian picture of agency: determine a problem, identify possible solutions according to given criteria, experiment with possible solution, repeat. However, none of the Green Recovery contributors takes up veganism as part of a strategic project of resistance, or even as an explicit means of recovery. As we turn to the narratives, then, the question at hand is not whether the contributors' resistant projects were successful or if they chose a likely candidate for a practice of freedom. Rather, I ask (1) do the narratives suggest that veganism helps subjects move away from a normative, patriarchal problematization of eating into something different? (2) If so, is eating within this new problematization more free than eating within the former problematization? I answer the first question in the affirmative, but my response to the second is more complicated. ${ }^{15}$

\section{Veganism as a Practice of Freedom}

The blog Choosing Raw, by Gena Hamshaw, hosts a regular series of guest posts entitled "Green Recovery". The blog focuses on plant-based nutrition, food, wellness, and issues of animal rights [21]. The Green Recovery (GR) series began in 2011 and, as of March 2014, includes twenty-five narratives

14 Within the normalizing patriarchal framework of eating, for example, rich and fatty foods — ones which do not promote the weight loss required by most of these projects - can only be enjoyed if they are controlled. We need prepackaged servings of indulgent treats because our appetites are out of control. These tiny treats are meant to assuage our unruly appetites, and in this way help us achieve our goals, since they will (supposedly) prevent "binging" on full size treats later.

15 I do not mean to suggest that veganism is the only possible practice of freedom with regard to patriarchal normalization. Rather, I simply offer it up here as a promising path suggested by these narratives. 
submitted by readers of the blog [5]. Twenty-four of the GR contributions belong to women, most of whom identify as or appear to be white, young, middle-class, and heterosexual. ${ }^{16}$ As Hamshaw describes it, the series is her "attempt to highlight stories of the many men and women who have moved beyond disordered eating patterns (at least in part) with the help of a plant-based diet" [5]. Hamshaw writes, "My goal with Green Recovery is not to suggest that veganism is the right choice for all disordered eaters, or that it's a "cure" for disordered eating, but rather to explore the notion that a world view in which food choices have political, ethical, and personal significance may actually heal, rather than hurt, people with traumatic histories with food" [5]. There are differences in the stories, but the overarching narrative remains the same: veganism-understood broadly as the exclusive consumption of plant-based foods for the reasons of animal and environmental welfare, and/or health - or something close to it, contributes to recovery from disordered eating or clinical eating disorders (EDs). ${ }^{17}$ In what follows, I draw out themes present in thirteen narratives in particular. These thirteen were chosen for their clarity of language and the way they resonated with aspects of the theoretical framework which I have elaborated above.

First I would like to draw out some of the ways in which the narratives reveal a reproblematization of eating. Bartkyian and Bordoian themes of a struggle for control, perpetual self-surveillance, self judgment and ranking, and the quest for unattainable standards are prominent in descriptions of the contributors' past "disordered" lives. Daphne writes: "Affixed to the mirror (or any reflection), I inspected my body constantly, fuming at the sight of any excess flesh. With time, suicidal thoughts emerged; I would have died to escape my imperfect body" [22]. "I honestly can't say that I remember a time when I didn't struggle with body image. From a very young age, I had always compared myself to others-always coming out on the bottom" [23]. Alex poignantly describes her suffering: "I was surrounded by darkness. My body was the enemy. I wasn't good enough, pretty enough, successful enough, or thin enough. My thoughts were consumed entirely by something inside me that was my voice, but not me. I was obsessed with my body and ways to perfect it. The anxiety and pain of life felt too out of control and life just didn't seem worth it anymore" [24].

Many of the authors describe themselves as having been obsessed with or "addicted to" food and eating, some over decades of their lives: "I cannot remember a time in my life when food was not a really big, bad deal" [25]. This focus on diet not only took up time and energy that might have been placed elsewhere, but rendered other interests and projects, including interpersonal relationships, subordinate to maintaining the diet: "My disorder left me isolated and depressed. My life revolved around my diet and I was a slave to it" [23].

Even those with "normal" body shapes and sizes struggled to control their appetites: "I couldn't understand why eating normally was so difficult for me" [26]. Alex writes: "I don't like to use

16 This demographic information is not usually explicitly given in the narratives, but can be inferred from the text and photographs of the authors.

17 The GR narratives and the Choosing Raw blog more often make interchangeable use of the terms "veganism" and "plant-based diet". Veganism strictly considered requires a focus on animals, while plant-based diets are more general and can be taken up for a variety of reasons (most commonly, health). Because all of these motivations play a role in the narratives, I remain ambiguous about the definition of the term. However, I do believe, as will become clear, that veganism centered in concern for animals and environment (what some might call "real" veganism) is most promising as a practice of freedom. 
numbers or percentages [to describe my disordered eating] because it's not so much about the weight as it is how sick my thoughts were. That's the true measure of sickness. Someone can be at a normal, healthy weight and be closer to death than you could ever imagine" [24]. Others, especially those who suffered from anorexia, emphasized their success at controlling their appetites and eating habits: "The combination of feeling disgusting in my own body and the feeling of life happening to me, without my control, led me to micro-manage the only thing I felt I really did have full control over-my body and what I chose to consume" [27].

Many authors describe themselves as having undergone a change in "mindset" [28] or "outlook" [26], a reframing [29], or a shift in "framework" [22] from the one just described to one within which food and eating have a less self-destructive place. Hamshaw herself and many other contributors describe their current "framework" as anchored in concern for animals and the environment. With this comes a focus on things outside the self. Hamshaw writes: "for those who become interested in the ethics of veganism - as I have - the lifestyle may offer a final escape from the terrible, isolated egocentrism that many ED sufferers experience. It helps us to shift attention from our weights, our clothing sizes, and every morsel that passes through our lips, to the plight of animals" [30]. Daphne says: "I developed a new framework, in which consideration for the origins and ethics of my food was more important than its caloric value, and I began to relax my stringent eating habits" [22]. "When I chose veganism, I made this decision to direct my thoughts and energies towards something much bigger than myself-The World!" [31]. ${ }^{18}$

Some contributors describe their new perspective as grounded in health and nourishment. ${ }^{19}$ The anonymous dancer writes: "My mindset as a whole was changed: I gained a strong sense that food should be nourishment, rather than a sort of punishment/source of stress and anguish, and this seemingly simple thought helped me in more ways than I could have imagined" [28]. "Eating wise, my outlook on food changed: food was no longer the enemy, but something made specifically to fuel my body and keep me healthy" [26]. Sarah says that this focus on health allowed her to stop thinking of food as something that needed to be controlled: "I reframed food in my mind as something that was healthy and necessary for life rather than something to control, limit and use to deal with my emotions" [29].

We can interpret these new "mindsets" in terms of the ethical framework I elaborated earlier. The telos, the "for the sake of which" eating is done is no longer an ideal body or control over appetites and desires. Eating is now for the sake of nourishment, a vibrant state of health; it is also (or otherwise) done for the well-being of animals and the environment. Appetite is no longer something of primary ethical interest. It seems more like the act of food consumption and the act of purchasing food are the most significant ethical substances. The mode of subjection seems to be on the one hand, one's sense of humanity and compassion, which call us to care about the suffering of sentient creatures and the degradation of the environment, and on the other hand, the body itself, which calls us to take care of it.

18 This shift to concern for what is "outside" the self, the relation of the self to others, and more specifically, to a community of both non-human and human animals echoes Tanke's claim that: "vegetarian subjectivities are more open to the holistic experience of existence, the political implications of personal ethics, and the strengths of community" [32] (p. 93).

19 Most contributors invoke both animals and environment and health as aspects of their new "outlooks", so I don't mean to suggest that they are exclusive. 
There is a clear complexity to this shift in "mindset", and many authors describe it as something that happened to them, rather than something they themselves did. The shift took time, sometimes periods of years, and happened gradually. Lauren writes: "I slowly felt more comfortable experimenting with new recipes, and old eating disordered thoughts that used to scream in my brain started dying down" [26]. Contributors do attribute the shift (at least in large part) to veganism but it is not a clear causal connection. Several authors had "tried" veganism previously and had not found it to have similar beneficial effects. Andrea says: "Any way of eating can be used a tool for strengthening one's connection with herself and fostering self-love or as a tool for self-abnegation and violence towards herself. A plant-based diet has served both of these functions for me" [33]. Some of the contributors continue to find a complete shift elusive. Sarah writes: "It seems that veganism, for me, has two faces. When life gets tough and I feel as though I can't cope, it's a way for me to be more controlling about food. When life is fine, veganism is a way that I can love food with freedom and creative expression" [29].

While delineating the precise causal mechanisms behind this shift are beyond the scope of this paper, it does seem that the reproblematization of food can be located, in large part, within the practice of veganism itself. The longer that the contributors practiced veganism, the more the new problematization solidified and gained strength relative to the normalizing patriarchal problematization that had been dominant. To build on Lauren's aural metaphor: the screaming of the internal disciplinarian was gradually drowned out by new voices with a new story about the purpose of eating and the meaning of food. Thus we can answer our first question in the affirmative: it does seem that veganism helps subjects reproblematize eating.

Now as to our second question: does this reproblematization make eating more free than before? From a certain "macro" perspective, the answer is yes. While Foucault's formulation of freedom is implicitly anthropocentric, Taylor [1] argues that the concept should be expanded to concern non-human animals as well. Emphasizing the importance of pleasure in practices of freedom, Taylor argues that the pleasures of the other-human and non-human alike-must be taken into account in our own practices [1] (pp. 79-80). Further, Taylor argues that the fact that we so often do not consider the pleasures of animals in our alimentary practices is a product of normalization itself, and thus impedes our own freedom. Thus, taking the freedom of animals into account through the practice of veganism is, in a significant way, more free than not doing so. In addition, Carol Adams [34] and others [35] have argued that gender oppression is inextricably linked to the oppression of non-human animals. In this sense, many humans will remain within situations of domination until the systematic domination of non-human animals is abolished. If this is the case, then practices of freedom must take into account the freedom of non-human animals as well as humans. It could be argued that veganism, as the refusal to benefit from and contribute to the exploitation and domination of non-human animals, is therefore a requirement for any practice of freedom. Thus, this reproblematization is more free in the sense that the contributors are now "playing the game" of power with less domination than before.

From a more "subjective" perspective the answer is less clear. Certainly this way of eating is less governed by normalizing, patriarchal power, but perhaps the new problematization of eating is normalizing or restrictive in some other way. In other words, it may not actually increase the number of possibilities for action, or cultivate the opening up of new possibilities; rather, it may be just as restrictive as before, albeit with slightly different content. There are aspects of the narratives which 
seem to be in line with our criteria for practices of freedom. Most notably, there is a proliferation of pleasures within the new problematization. Food itself is a described as a source of great pleasure, and not because of (or in spite of) its supposed effects on the body. Daphne explains that while within the grip of her eating disorder, "the tickle of hunger became my only pleasure. I grinned as that tickle gave way to pain, and felt superior to anyone who succumbed to his or her taste buds" [22]. She then describes an unexpected "infatuation" with food, which grew throughout her recovery: "I started preparing my own meals, and found it unexpectedly enjoyable. Such intimate contact with food captivated me; squishing a soft, juicy mango with my hands was inexplicably therapeutic" [22]. Alex writes: "I'm learning to love food again and with my hunger cues back, I relish the chance to explore what veganism has to offer" [24]. "Veganism allowed me to eat for both pleasure and nourishment. Eating was no longer a chore" [23].

In addition, many contributors describe a new openness to the possibilities life has to offer. Many learn to cook, others take up activist work, and others focus on interpersonal relationships. The "anonymous dancer" puts it this way: "True, it's easier said than done, but at the end of the day, when you're able to sit down and realize that today, you laughed and loved and lived, rather than obsessively planned each moment around food and exercise, it's a giant step in the right direction" [28]. ${ }^{20}$

The narratives reveal pleasures and an openness to possibilities, particularly interpersonal possibilities, both of which echo our criteria for practices of freedom. There is research suggesting that both of these characteristics are common qualities of the practice of veganism. ${ }^{21}$ However, there are also aspects of the narratives that are less promising. While nearly all contributors note their commitments to animal welfare, many contributors explicitly center their new eating habits in health. Eating is now a way to fulfill the needs of the body. It's true that this problematization seems to undercut a lot of the suffering that the patriarchal problematization generated: as Rachel says, "I no longer have the guilt I did when eating, because I know that what I'm putting into my body is exactly what it needs and craves" [37]. However, health can engender its own rigid rules about what foods and practices are permitted. And health, as internal to the body, natural and innate to us qua biological creatures, is a normative concept par excellence. Talia Welsh reminds us that "the goal of a healthy body, and the subsequent control that pursuing such a goal requires, can be equal in discipline to, if not more disciplinary than, dieting to obtain an aesthetic standard" [38] (p. 41). I will return to this worry in more detail at the end of the paper, but suffice it to say for now that a "healthist" problematization of eating risks being just as normalizing as the patriarchal one.

Even a commitment to animals can be problematic. GR contributor Jennifer raises the spectre of vegan purity, an ideal requiring the elimination of animal products and reliance on the exploitation of animals in all areas of life, far beyond food. Purity of any kind is nearly impossible to achieve, and draws sharp lines around what sorts of actions are permitted. Moreover, as Jennifer's story reveals, it lends itself easily to normalized rankings: "I was frustrated, felt inferior to other vegans, wanted to

20 Many Foucauldians would be skeptical, and rightly so, that a phenomenological freedom is indicative of any real freedom. But I think that in conjunction with the more general, "external" picture of the shift here, it is indicative of something meaningfully free.

21 Cole emphasizes the "hedonism" of veganism and vegetarianism, which includes the pleasures of eating but also preparing one's own foods and cultivating creativity in the kitchen [36] (pp. 712-713). See also Tanke [32] (p. 93). 
belong, and had a strong desire to do things perfectly" [31]. As Tanke writes, "it is always possible to live more and more cruelty free and hence gain greater standing vis-à-vis the norm" [32] (p. 86). ${ }^{22}$

A unequivocal response to whether or not the GR contributors' new problematization of eating is more free in this "subjective" sense is therefore elusive. Many seem to be caught up in a potentially normalizing healthist regime, and there is the risk of becoming beholden to normative vegan purity — both of which may severely limit possibilities for action. Nonetheless, the narratives do indicate that the practice of veganism can help subjects become a little less governed by normalizing patriarchal power-which is an impressive feat in itself. Before we move onto the consideration of objections to this claim, the claim's limitations must be noted. Bordo and Bartky's protestations aside, there are good reasons to believe that there are significant differences between the ways that members of different races, ethnicities, classes, and sexualities relate to the feminine norm and to veganism as a practice $[1,39,40]$. These differences may affect the outcomes or even the possibility of ethical experimentation with veganism. For instance, Taylor notes that non-dominant cultural groups may view veganism, and the way it necessitates a rejection of certain cultural cuisine, as a "threat to cultural diversity" [1] (p. 81); members of these groups who take up veganism might be seen as cultural traitors in a way that white middle-class women would not experience. A. Breeze Harper's work [39,40] reveals the complex ways in which black American women relate to veganism. Given the general homogeneity of the GR contributors, my claims here are not generalizable to those who find themselves differently located with relation to the norm and veganism. In other words, this research suggests that veganism is a promising practice of freedom for white, young, middle-class, heterosexual women - and it does not speak to those in different groups.

\section{Objections}

I have argued that veganism is a potential practice of freedom with regard to patriarchal normalization, at least for North American women belonging to dominant groups. In other words, it might be a practice that helps some women shake off disordered eating habits and the subjectivity produced through those habits. In this final section, I address two objections to this claim. First, there have been recent studies suggesting that vegetarianism is itself an eating disorder, or is at least closely linked to eating disorders and dieting. If this is correct, it may be a counter-example to my claim, since dieting and disordered eating are taken as manifestations of patriarchal normalization and these seem to be present at higher rates amongst self-reported vegetarians than omnivores. Perhaps veganism does not help "shake off" patriarchal normalization after all. After dismissing this possibility, I return to my worry about the normalizing regime of healthism. As so many of the GR contributors express healthist concerns, I consider whether this is something inherent to veganism, to veganism practiced by those with eating disordered pasts, or, perhaps, to North Americans in general. If it is inherent to veganism itself, then perhaps veganism is "too dangerous" for purposes of ethical experimentation. I suggest that this is not the case.

22 Tanke argues that conceiving of veganism as a Foucauldian practice of the self rather than as a normative set of moral rules (as many moral philosophers do) will help to undercut this problem [32]. 


\subsection{Vegetarianism is an Eating Disorder}

The first objection arises out of several studies in dietetics linking vegetarianism, dieting, and/or eating disorders [41-44]. ${ }^{23}$ The general message is that vegetarians-who, as consumers of milk and eggs, are already a broader category than vegans - are more likely to display dieting or disordered eating behaviours and "attitudes" than omnivores. ${ }^{24}$ The studies suggest that vegetarianism may be taken up by dieters and disordered eaters as some sort of "cover" for their problematic eating habits, or, because of its restrictive nature, vegetarianism is a manifestation of, or at least impedes recovery from, disordered eating.

These studies can be criticized on several levels [36], but I want to focus on two interconnected flaws, which arise directly from the theoretical framework at work in this essay. To begin, I do not deny that vegetarian or vegan diets can be used as a weight-loss tool, or as a "cover" for dieting or eating disorders, and I certainly do not deny that some people with eating disorders are also vegetarians or vegans (Sarah's story and others show us as much). But if Taylor is correct, then diets cannot be analyzed as atomistic sets of food choices; they need to be understood within an ethical framework. These studies fail to do so. They either did not ask for motivations or reasons for being vegetarian at all (which would be a thin proxy for an ethical framework), or if they did (for example, [42]) they did not track whether or not these motivations made differences in the study results. Moreover, all of the studies not only include "semi-vegetarians" in their samples, but the samples are predominantly made up of semi-vegetarians. In one study $23 / 30$ "vegetarians" in the study were semi-vegetarian [42]. In another, out of 108 current vegetarians, over $85 \%$ consumed milk and eggs, nearly half ate fish, and $25 \%$ ate chicken [44]. ${ }^{25}$ Semi-vegetarianism is a practice that makes a good deal of sense if one is hoping to cut calories or fat from one's diet; but not so much sense if you are committed to animal welfare. Through the inclusion of semi-vegetarians, and more generally, by excluding ethical frameworks even in a thin sense, the studies are likely tracking those practicing within more conventional ethical frameworks - dieters, disordered eaters, and those interested in health - than those practicing vegetarianism for the sake of animals or the environment, the ethical framework which I

23 Vegetarianism is a diet that excludes all animal flesh, but can include eggs and dairy. These studies consider veganism a subset or more exclusive version of vegetarianism.

24 To summarize the findings in more detail: Lindemann et al. [43] argue that vegetarianism and eating disorders are "intertwined" phenomena. Their study found that vegetarians had higher rates of anorexic attitudes and behaviours than the non-vegetarian control sample. These behaviours are also found in other groups of dieters. They suggest that vegetarianism, as a form of "cognitively regulated eating" may be a risk factor for eating disorders. Klopp et al. [42] suggest that among college women, vegetarians were "more likely to display disordered eating attitudes". Robinson-O'Brien et al. [44] had a larger study that looked at both current and former vegetarians, arguing that "current vegetarians may be at risk for binge eating with loss of control, while former vegetarians may be at increased risk for extreme unhealthful weight-control behaviors" (p. 648). They suggest that clinicians question the motives of vegetarian adolescents or those who have "experimented" with it. Bardone-Cone et al. [41] argue that those individuals with eating disordered pasts are more likely to become vegetarian for weight-related reasons. They note that vegetarianism is unlikely to be the cause of eating disordered behaviour, but rather is adopted by those who already display such behaviours. They suggest that vegetarianism may impede recovery.

Moreover, one study [44] noted that the weight control behaviours were more common amongst semi-vegetarians than so called strict vegetarians_-which seems to support my argument here. 
have been suggesting is potentially transformative (see Cole for more criticisms of including semi-vegetarians in studies on vegetarianism, [36] (p. 713)). Since nearly all of the GR narratives note some commitment to animals and the environment, I do not believe that these findings undermine my claim. In short, ethical practices are meaningless without the framework within which they are intelligible and possible. The exclusive or not so exclusive consumption of plant-based foods may reinforce normalized selves, or undermine normalization. I am only suggesting that within certain frameworks the practice of veganism seems to be a practice of freedom, one that can move subjects away in some significant way from patriarchal normalization and into something less restrictive. ${ }^{26}$

\subsection{Veganism and Healthism}

The second objection I consider returns to the link between veganism and health. Even if I am correct that veganism can help people become a little less governed by patriarchal normalization, I worry about the prevalence of concern with health in the Green Recovery narratives and the possibility that it reflects the contributors' inscription within a similarly problematic normalizing regime, namely healthism.

I do not want to say that we should not care about health, or that we should not use good scientific evidence about how the body functions to inform our choices and behaviors. But, like Talia Welsh, I am concerned with the intensification and totalization of health as a governing norm. Welsh calls this is "good health imperative", which is coming to govern all forms of "modifiable behaviors" [38] (p. 34) — not just food and exercise. Welsh is particularly concerned with the way healthism negates all pleasures that are not considered healthy: "The tightest noose around bodily pleasures today is the set of norms regarding health. I cannot engage in any behavior without processing it as healthy/good or unhealthy/bad" [38] (p. 43). While health norms may allow for a more "wiggle room" than patriarchal norms of femininity (at least if one adheres to some sort of "everything in moderation" view), they can become extremely exclusive and rigid. In addition, Welsh argues that a healthist normalizing regime constitutes problematic forms of subjectivity akin to those constituted by patriarchal normalization, including an antagonistic relationship to the body. ${ }^{27}$

26 There is a related objection: One might argue that subjects who leave behind disordered eating for veganism do not constitute themselves any differently. Such people have a psychological need for strict rules and regulations about eating; mainstream dieting rules filled that role for a while, and now it is vegan rules. The particular set of rules by which one eats is largely irrelevant; it is the fact that one needs the rules that determines one's subjectivity. As I just mentioned, someone could easily use veganism as a weight-loss diet. If so, then the shift to veganism would mean little more to the subject than a shift to South Beach diet or Atkins. But given the shift in ethical framework-not just the contents of one's diet, but the entire ethical framework within which the diet makes sense - I do believe that the subject must change. Of course, this will be unconvincing if one rejects Taylor's claim that alimentary practices are central self-constituting practices. But even then, the GR narratives suggest that "vegan rules" allow for more joy, more pleasure, and more time and energy for non-eating related activities than mainstream dieting rules. In this sense, they are preferable, even if they do not alter some psychic need for rules and regulations about eating. Thanks to Cressida Heyes for raising this worry.

Welsh [38] also raises the connection of health imperative to economic and social factors, and makes health into an individual issue and responsibility—rather than one with structural economic, social causes. Thus there are structural oppressions at play here as well. 
The GR narratives suggest that an "obsession" with health-playing out in the same way an obsession with body and food played out in the patriarchal framework-is a real risk for the contributors. As we have seen, health is central to many of the GR contributors' lives, and is a grounding factor for their new eating practices. Some contributors note their struggle to care about health but not allow it to become obsessive [25,26]. Given the current political and social insistence on health, and with the (not unrelated) advent of "plant-based lifestyle" advocates, who promote a "plant-based" diet for purely health-related reasons, eating vegan within healthist terms is easier than ever. And with the capacities cultivated through disordered eating-self-surveillance, attention to detail, extensive knowledge about food-those who suffered from disordered eating may find themselves both attracted to and well-equipped to "succeed" within this normalizing schema. Recently Hamshaw expressed particular concern with this trend, put forth in terms of orthorexia: "an obsession with eating foods that one considers healthy" and "a medical condition in which the sufferer systematically avoids specific foods in the belief that they are harmful" [45]. She notes that many readers have requested she address the issue, and admits to having suffered from it herself. Because the Foucauldian account of freedom emphasizes openness to possibilities, going from one normalizing regime - patriarchal normalization - to another-healthism - is not increasing one's own freedom (though, as we have seen, we may still have freedom-based "macro" reasons for taking it on). If healthism is a likely outcome, perhaps veganism is too "dangerous" an ethical experiment —at least, for those who have eating disordered pasts. Perhaps instead, we should look for alimentary practices that are further removed from concerns about health.

Despite the prevalence of healthist themes in the GR narratives, I do not think that this tendency is inherent to veganism broadly construed. The focus on health that makes an obsession with health possible or even likely in the narratives is in part an artifact of the community involved in Hamshaw's blog, and its focus on nutrition and raw foods, rather than an inherent aspect of veganism. There are many vegan communities that are less focused on health than the one that gathers around Hamshaw's blog; more politically inclined groups, like anti-racist and anti-capitalist vegans are good examples, and also vegans who congregate around "junk foods". ${ }^{28}$ In these groups, animal rights, environmental welfare (and perhaps other political concerns) trump concerns about health, though health may also be valued. Therefore, there is no reason to suspect that vegans in general are any more susceptible to healthism than those with "regular" diets. If Welsh is correct, everyone in North American society should be concerned about the creep of the good health imperative into all areas of life.

Even for those with an eating disordered past and an interest in health, healthism is not an unavoidable trap. Green Recovery host Gena Hamshaw has worked her own way out of it, emphasizing the importance of non-health related pleasures in maintaining what we might call a "healthy" perspective on health:

The lesson I've learned, though, is that healthful choices can coexist peacefully-even synergistically — with ones that are (superficially, anyway) less healthful. My love of

28 The VegNews May/June 2013 issue [46] includes articles on punk and hip-hop vegan communities, and Breeze Harper's work, for instance [39,40], provides a critical race perspective on veganism, which includes health but does not privilege it over concerns about justice, for instance. For some vegan junk food see [47]. 
vegetables is not undone by the extra cups of coffee I drink when I know I've really had enough, the vegan treats that delight my senses, no matter how sweet they are, the late nights I sometimes spend out or listening to music or chatting with friends when sleep might be more prudent. My life can accommodate all of those pleasurable moments, and many more [45].

\section{Conclusions}

"I think that the main ethico-political choice we have to make every day is to determine which is the main danger." Michel Foucault (quoted in [4], p. 111).

Using a Foucauldian theoretical framework, I have argued that veganism is an ethical practice that can constitute subjects who are less governed by normalizing patriarchal forms of power. I read the Green Recovery narratives as describing such a transformative ethical shift, though, importantly, this shift was not intentionally cultivated as resistance. One of the consequences of this inadvertence is that I have worries about unequivocally proselytizing veganism as a practice of freedom. For one, a genuine concern with animals is central to almost all the GR stories; without this I am not sure that veganism would have such powerful effects on the self. Taking up veganism as a way to "ungovern" oneself from patriarchal normalization may not have the same effects as it does on those who take it up, at least in part, for the sake of animals. Further, as I have discussed, there are potential dangers of veganism for those recovering from disordered eating, in particular co-optation by healthism. But in the end, these considerations should not discourage anyone from ethically experimenting with veganism. If Taylor and Adams and others are correct, veganism is a practice of freedom at least in the sense that it allows us to eat with the least amount of domination possible. Finally, I do not think we should dismiss any practice that has the potential to help us shrug off some of the "unbearable weight" of patriarchal normalization. Even if it does not work, there may be joys to be found in the experimenting.

\section{Acknowledgments}

The author is supported by the Social Sciences and Humanities Research Council, and Georgetown University Philosophy department.

\section{Conflicts of Interest}

The author declares no conflict of interest.

\section{References and Notes}

1. Taylor, C. Foucault and the Ethics of Eating. Foucault Stud. 2010, 9, 71-88.

2. Bartky, S.L. Foucault, femininity, and the modernization of patriarchal power. In Femininity and Domination: Studies in the Phenomenology of Oppression; Routledge: New York, NY, USA, 1990.

3. Bordo, S. Unbearable Weight, 10th anniversary ed.; University of California Press: Berkeley, CA, USA, 2003. 
4. Heyes, C.J. Self-Transformations: Foucault, Ethics, and Normalized Bodies; Oxford University Press: New York, NY, USA, 2007.

5. Hamshaw, G. Green Recovery. Available online: http://www.choosingraw.com/green-recovery/ (accessed on 1 March 2014).

6. Foucault, M. Discipline and Punish: The Birth of the Prison; Vintage Books: New York, NY, USA, 1995.

7. McWhorter, L. Bodies and Pleasures: Foucault and the Politics of Normalization; Indiana University Press: Indianapolis, IN, USA, 1999.

8. Foucault, M. The Subject and Power. In Power; Faubion, J.D., Ed.; Hurley, R., Transl.; The New Press: New York, NY, USA, 2000.

9. Cahill, A.J. Masculine Sex Objects. In Overcoming Objectification: A Carnal Ethics; Taylor \& Francis: New York, NY, USA, 2011; pp. 56-83.

10. Chastain, R. Fat: The Owner's Manual; Sized for Success Multimedia: Austin, TX, USA, 2012.

11. Foucault, M. The Ethic of the Concern for the Self as a Practice of Freedom. In Ethics: Subjectivity and Truth; Rabinow, P., Ed.; The New Press: New York, NY, USA, 1997.

12. Foucault, M. On the Genealogy of Ethics: An Overview of a Work in Progress. In Ethics: Subjectivity and Truth; Rabinow, P., Ed.; The New Press: New York, NY, USA, 1997.

13. Lebesco, K. Revolting Bodies? The Struggle to Redefine Fat Identity; University of Massachusetts Press: Amherst, MA, USA, 2004.

14. Farrell, A. Fat Shame: Stigma and the Fat Body in American Culture; New York University Press: New York, NY, USA, 2011.

15. Oksala, J. Foucault on Freedom; Cambridge University Press: New York, NY, USA, 2005.

16. Foucault, M. Sexual Choice, Sexual Act. In Ethics: Subjectivity and Truth; Rabinow, P., Ed.; The New Press: New York, NY, USA, 1997.

17. Foucault, M. Michel Foucault: An Interview by Stephen Riggins. In Ethics: Subjectivity and Truth; Rabinow, P., Ed.; The New Press: New York, NY, USA, 1997.

18. McWhorter, L. Racism and Sexual Oppression in Anglo-America: A Genealogy; Indiana University Press: Indianapolis, IN, USA, 2009.

19. Foucault, M. Sex, Power, and the Politics of Identity. In Ethics: Subjectivity and Truth; Rabinow, P., Ed.; The New Press: New York, NY, USA, 1997.

20. O'Leary, T. Foucault and the Art of Ethics; Continuum Publishing: London, UK, 2002.

21. Hamshaw, G. About. Available online: http://www.choosingraw.com/about/ (accessed on 5 March 2014).

22. Hamshaw, G. Green Recovery: Daphne's Triumph Against “Ana”. Plus, my NYC Dining Bucket List. Available online: http://www.choosingraw.com/green-recovery-daphnes-triumph-againstana-plus-my-nyc-dining-bucket-list/ (accessed on 14 February 2014).

23. Hamshaw, G. "What Healthy Truly Means": Quincy's Green Recovery Story. Available online: http://www.choosingraw.com/what-healthy-truly-means-quincys-green-recovery-story/ (accessed on 15 February 2014).

24. Hamshaw, G. "I Never Thought I'd Develop an Eating Disorder" Alex's Raw Recovery Story. Available online: http://www.choosingraw.com/i-never-thought-id-develop-an-eating-disorderalexs-raw-recovery-story/ (accessed on 15 February 2014) 
25. Hamshaw, G. Green Recovery: Wendy Puts an End to Compulsive Eating Through a Plant-Strong Diet. http://www.choosingraw.com/green-recovery-wendy-puts-an-end-to-compulsive-eatingthrough-a-plant-strong-diet/ (accessed on 14 February 2014).

26. Hamshaw, G. "I couldn't understand why eating normally was so difficult for me": Lauren's Green Recovery Story. Available online: http://www.choosingraw.com/i-couldnt-understandwhy-eating-normally-was-so-difficult-for-me-laurens-green-recovery-story/ (accessed on 14 February 2014).

27. Hamshaw, G. Green Recovery: Casey Lorraine on Finding Freedom through Wholesome Food. Available online: http://www.choosingraw.com/green-recovery-casey-lorraine-on-findingfreedom-through-wholesome-food/ (accessed on 14 February 2014).

28. Hamshaw, G. Green Recovery: One Dancer's Harrowing Story. Available online: http://www.choosingraw.com/green-recovery-one-dancers-harrowing-story/ (accessed on 14 February 2014).

29. Hamshaw, G. Green Recovery: Sarah Gives Veganism a Second Chance. Available online: http://www.choosingraw.com/green-recovery-sarah-gives-veganism-a-second-chance/ (accessed on 14 February 2014).

30. Hamshaw, G. Green Recovery: The Plant-Based Road to Healing from Disordered Eating. Available online: http://www.choosingraw.com/green-recovery-the-plant-based-road-to-healingfrom-disordered-eating/ (accessed on 1 February 2014).

31. Hamshaw, G. "Veganism is a Life Saving Journey, Not a Destination to Perfect Oneself". Jennifer's Story. Available online: http://www.choosingraw.com/green-recovery-veganism-is-a-lifesaving-journey-not-a-destination-to-perfect-oneself-jennifers-story/ (accessed on 14 February 2014).

32. Tanke, J. The Care of the Self and Environmental Politics: Towards a Foucaultian Account of Dietary Practice. Ethics Environ. 2007, 12, 79-96.

33. Hamshaw, G. Green Recovery: Andrea Falls in Love with How She Feels on a Plant-Based Diet. Available online: http://www.choosingraw.com/green-recovery-andrea-falls-in-love-with-howshe-feels-on-a-plant-based-diet/ (accessed on 20 February 2014).

34. Adams, C.J. The Sexual Politics of Meat: A Feminist-Vegetarian Critical Theory; Continuum International Publishing Group: New York, NY, USA, 1990.

35. Animals and Women: Feminist Theoretical Explorations; Adams, C.J., Donovan, J., Eds.; Duke University Press: Durham, NC, USA, 1995.

36. Cole, M. Asceticism and hedonism in research discourses of veg*anism. Br. Food J. 2008, 110, 706-716.

37. Hamshaw, G. Green Recovery: Rachel Finds Balance and Compassion. Available online: http://www.choosingraw.com/green-recovery-rachel-finds-balance-and-compassion/ (accessed on 14 February 2014).

38. Welsh, T.L. Healthism and the Bodies of Women: Pleasure and Discipline in the War against Obesity. J. Fem. Scholarsh. 2011, 1, 33-48.

39. Harper, A.B. Sistah Vegan: Black Female Vegans Speak on Food, Identity, Health, and Society; Lantern Books: Brooklyn, NY, USA, 2010. 
40. Vegans of Color, Racialized Embodiment, and Problematics of the "Exotic". In Cultivating Food Justice: Race, Class., and Sustainability; Alkon, A.H., Agyeman, J., Eds.; Massachusetts Institute of Technology: Cambridge, MA, USA, 2011.

41. Bardone-Cone, A.; Fitzsimmons-Craft, E.E.; Harney, M.B.; Maldonado, C.R.; Lawson, M.A.; Smith, R.; Robinson, D.P. The Inter-relationships between Vegetarianism and Eating Disorders among Females. J. Acad. Nutr. Diet. 2012, 112, 1247-1252.

42. Klopp, S.A.; Heiss, C.J.; Smith, H.S. Self-reported Vegetarianism may be a Marker for College Women at Risk for Disordered Eating. J. Am. Diet. Assoc. 2003, 103, 745-747.

43. Lindeman, M.; Stark, K.; Latvala, K. Vegetarianism and Eating-disordered Thinking. Eat. Disord. 2000, 8, 157-165.

44. Robinson-O’Brien, R.; Perry, C.L.; Wall, M.M.; Story, M.; Neumark-Sztainer, D. Adolescent and Young Adult Vegetarianism: Better Dietary Intake and Weight Outcomes but Increased Risk of Disordered Eating Behaviors. J. Am. Diet. Assoc. 2009, 109, 648-655.

45. Hamshaw, G. NEDA Week 2014: Considering Orthorexia. Available online: http://www.choosingraw.com/neda-week-2014-considering-orthorexia/ (accessed on 28 February 2014).

46. The Music Issue. VegNews, May/June 2013.

47. Fuck Yeah Vegan Junk Food. Available online: http://fuckyeahveganjunkfood.tumblr.com/ (accessed on 10 March 2014).

(C) 2014 by the author; licensee MDPI, Basel, Switzerland. This article is an open access article distributed under the terms and conditions of the Creative Commons Attribution license (http://creativecommons.org/licenses/by/3.0/). 